\title{
Research on Sustainable Development of Folk Culture Industry in Henan
}

\author{
Bianling Zhang \\ School of Art and Design \\ Huanghe Science and Technology College \\ Zhengzhou, China, \\ E-mail:24196102@qq.com
}

\begin{abstract}
Henan province has a long history, rich folk culture resources. The forms of folk culture are diversified. But in terms of the development strength of Henan folk culture resources, it starts relatively late on the whole and the development is at an early stage. It hasn't formed regional bands. Problems are very prominent, such as no obvious brand advantage of folk products, small industry scale, low resources conversion rate, lack of innovation and talents. In order to realize benign development of Henan folk culture industry, it is necessary to use advanced regional culture idea, implement the combination of brand strategy and creation of creative industry of folk culture, integrate available resources, build the market of Henan folk culture industry and excavate innovative approaches to promote the development of folk culture industry.
\end{abstract}

Keywords-Henan folk custom; culture; industry; development

\section{INTRODUCTION}

Folk custom refers to the living culture created, used and inherited by the general public in a country or nationality. [1] It is series of substantial and spiritual cultural phenomenon formed by ordinary working people in daily production and life. It has universality, variability and inheritance. Folk culture is the basis as well as an important part of ethnic culture. It is the unique cultural phenomenon of a nation and created by human in long-term production and life under different regions, customs and cultural background. After continuous accumulation and evolution, it has become the culture with different characteristics and modes. It is the problem demanding prompt solution about how to effectively protect and reasonably develop these folk cultures and promote the development of folk culture industry.

For a long time, the research on folk culture is often limited to the category of academic research and will not involve problems such as the sales of folk culture products; when referring to problems such as development, production and sales of folk culture products, enterprises also seldom communicate with specialists and scholars of folk custom. Culture separates from industry, which have many disadvantages and make folk products lack academic level, artistic style and cultural concept. Nowadays, information industry develops rapidly and market competition is intense.
It is the sacred mission endowed by the time for us about how to open up the market of folk culture industry, strengthen the "hematopoietic" function of folk cultural undertakings, make cultural studies and product development combine with each other, learn from each other's strong points to offset each other's weakness, form scale effect and serve local economy and culture. It's also one of the ways of productive protection, a new topic in front of workers of folk culture and even an important channel to inherit folk culture.

\section{CHANGE IDEA AND IMPROVE THE IDEOLOGICAL UNDERSTANDING FOR INDUSTRIALIZATION OF FOLK CUlture}

With continuous deepening of the reform and opening-up policy, information technology and network media develop at top speed, more fiercely strike the culture and thoughts. In order to realize the industrialized development of folk culture, we must change thoughts and concepts.

Firstly, folk culture workers must clearly know that to realize the industrialization of folk culture is not easy and cannot be completed in a short duration of time. It is a longterm difficult work. We must make up our minds of fearing neither hardship nor weariness, take the road of cultural industrialization and develop the market of cultural products so that local economy can be prospered. It is obvious that if cultural workers want to get out of the trouble, they must free their minds, overcome the emotions of being afraid of difficulties, make the determination to develop folk culture products, realize that the disconnection between cultural studies and product development is caused by planned economy and cannot keep pace with changes of the times. It is the only road for us to achieve industrialization of folk culture by taking the road of combination of folk culture products and markets.

Secondly, folk culture workers should get a clear understanding of the situation and have sense of urgency and responsibility. At present, the strategy for economic development promoting from China's South-East coastal areas to Midwest areas is the golden and once-in-a-lifetime opportunity for Henan in hinterland of Central Plains. It is also a hard-won development opportunity for provinces and cities in Midwest areas. Prospering local economy is related to the overall situation of folk culture development in our 
country. Especially the folk culture in Central Plains concerns the future of cultural development in Central Plains and also has relationship with general situation of construction of Central Plains Economic Region. Prospering folk culture industry in Central Plains is an indivisible and important part in economic and cultural system in Henan province.

Thirdly, folk culture workers should enhance confidence, and see clearly the possibility of industrialization of folk culture and the tasks of development of folk culture. The rapid development of information technology drives the process of knowledge economy, "Human is moving into an economic era that takes the occupation and configuration of intellectual resources and the production, allocation, use and consumption of knowledge as the most important factors. [2] The 21 st century is the era when innovative and high technology develops rapidly. It is necessary for us to comply with the trend of development of information technology industrialization, make the economy that depends on folk culture gradually move toward industrialization, form scale and create brands. For a long time, the protection, arrangement and development work of folk culture in Central Plains have achieved remarkable progress. Competitive products of folk culture in Central Plains appear continuously. The overall strength and competitiveness and the development and utilization efficiency have been promoted obviously and created new situation of innovative development of folk culture in Central Plains. The so-called knowledge economy takes high technology industry as the first main industry and has become global wave. Comrade Deng Xiaoping once said, "Science and technology are the primary productive forces". That is to say, knowledge information should become basic element of modern production. The economical industry of sustainable development that depends on intellectual resource is the driving force of modern economy development. It uses new knowledge, new technology and new information to arrange, excavate and develop resources of folk culture.

\section{CREATE THE IDEA OF DEVELOPMENT OF FolK CULTURE INDUSTRIALIZATION}

The development of folk products is to seek social benefits, at the same time, makes it become unique cultural industry and meet people's multi-level spiritual and cultural pursuits. In recent years, the utmost abundance of material life increases people's requirements for diversified and multi-level spiritual and cultural products. The development of folk culture products needs cooperation of many aspects and it is not an easy thing. Striving to achieve three combinations, we can carry forward Central Plains Culture and prosper cultural industry.

Firstly, combine product development with research on folk customs. Folk culture resources in Central Plains are abundant. It is the solid foundation of Henan province to promote the development of cultural industrialization and create well-known brands of cultural industry. Folk experts should be well-trained and proficient in professional work, so that they can break through key technology of cultural industry and develop new cultural industry. They are in the right position to speak about which kind of folk culture has characteristics and which kind of folk product can be developed. So research team of folk culture is the talent team of the development of folk products. Entrepreneurs are familiar with markets. They know clearly about which kind of product has good market outlet and is favored by customers. But they have no idea about folk products and how to choose it. If we call up talent team of folk custom and entrepreneurs and let them learn from each other and exchange ideas, won't we be able to let the exploitation of folk products and industrialized development of folk custom take new steps? If we make the main energy of experts who study folk customs turn to the development of new products, change their research achievements into productive forces, strive to combine cultural study and development of folk products and make their innovative wisdom produce economic benefits, and then endow these new folk products with the smart commercial awareness of entrepreneurs, won't we be able to hasten the production of new type of folk culture forms in Central Plains and promote the development of folk culture in Central Plains to shine with vitality?

Secondly, combine folk culture with tourism industry. Under the current industry background, tourism resources in various regions become new economic growth point. Tourism activities belong to cultural consumption, because most tourism activities have abundant cultural connotation. The combination of folk culture and tourism industry can not only continuously enrich contents of tourism industry, but also effectively publicize folk culture and inject new vitality to tourism industry with the help of tourism landscapes. The development of tourism industry drives the development of industries such as local business, enterprises and hotel and restaurant industry. It is an emerging industry with multiple functions and then promotes the development of local economy, expands market requirements and increases opportunities for employment. Tourism resource is a kind of existence on cultural significance and can meet tourists' psychological demands. If tourism industry becomes more and more prosperous, folk culture will also develop better and better. They bring out the best in each other.

Thirdly, shape multi-level and unique tourism products, then it will have less competition and can attract customers. Because folk tradition and folk customs in various regions are different, there are diversified folk culture products, which are unique and have large stock. They have few competitors. For example, Jun porcelain, Nigugu, New Year wood-block print and Ninigou belong to static products. They have hardly any competitor in the market. This part of folk culture is likely to become brand products and provide opportunities for the marketing of folk culture products and bring a favorable turn for the market. There is a kind of dynamic products, such as Shaolin Kung Fu, Pangtzu of Honan, Large Bronze Performance in Jia County, etc. They show the rich folklore characteristics in the local area. If we depend on tourism landscapes and attractions, combine static products and dynamic products of folk culture, and combine colorful folk products with folk activities and vitalize folk culture, it is easy for us to promote the fine reputation of 
tourism resources and get more ideal social and economic benefits and meet different requirements of tourists at different education levels. Then folk culture will form its characteristics and brand products will be produced.

\section{Make Product Positioning ACCuRAte, STRENGTHEN PRODUCT MARKETING}

The trend of the present era is to return to nature. The development of folk products also should grasp market information, follow rules of the market. Under the impact of this kind of social trend, people need the return of the soul and culture. If the launch of folk culture products wants to form industry scale, it must strictly designedly develop products according to market requirements, seize opportunities and launch "natural products" and "green products", give back the pure, simple and natural land to people. Because these products can cater to the psychology of modern people, stimulate people's new requirements, effectively use resources of them and show the original ecological side of them and open markets in experience field for the marketing of folk culture products, it will bring boundless vitality for folk culture industry.

It is the prerequisite for folk products to gain a large share of the market by understanding market condition and analyzing the market. The proposition and establishment of development mechanism of folk culture products not only help the theoretical development of folk culture products, but also have realistic instructive significance in guiding the design and exploitation of folk culture products in practice and promote the sales promotion and marketing campaign of folk culture products. The product positioning should notice the following aspects: firstly, it must highlight local features and develop featured products. Many featured products have tenacious vitality and great exploitation potentiality, but they still exist in the folk and haven't been developed. In reality, things that have more characteristics will have more development value and market outlets. Secondly, folk products should use local materials and be processed locally to reduce intermediate links and lower the cost. So the profits will be improved naturally and economic income is increased. Thirdly, for products with less investment and quick returns, if the development cycle of product is long with many intermediate links and more investments in manpower and financial resources, the turnover of capital will be slow and the benefits will be less, which are easy to dampen the enthusiasm of the masses. So it is necessary to take products with "short development recycle, less investment and rapid turn over of capital" as the preferred products, so that we can achieve good economic benefits in a short period of time.

Folk culture always has very strong regionalism and folk characteristics and profound mass foundation. We can reach the final conclusion by developing products with targeted aim, analyzing and understanding consumption psychology of the public, knowing market distribution and market share of products and then doing market survey repeatedly. Blindly developing and producing without seeing objectives will result in waste and screw up brand image. There are many common ways of market survey, such as general survey, sampling survey, typical survey, questionnaire survey, case survey and home interview, etc. Then we can invite folk experts and entrepreneurs to demonstrate and check, so we can avoid detours and wasting. In this way, the product positioning will be reasonable and reliable. People in different countries, nations, ages and genders have different requirements. So we should carry out market research and market forecasting in an organized way and purposefully, connect products with marketing, and then the development space of folk culture products will be broader and broader. The development of folk culture products also has positive meaning on carrying forward folk culture. It can meet people's cultural requirements in multiple aspects, create considerable economic value and make contribution to the development of regional economy.

For a long time, exploring the connection of folk culture and cultural creative industry has promoted the development of industrialization of folk culture in Central Plains and strengthened the cooperation and win-win situation between folk culture and media industry in Central Plains and also played an important role in construction of folk culture in our country. Building new mechanism for the folk culture development in Central Plains helps to protect and develop folk culture and promote the prosperity and development of folk culture and takes a "Road in Central Plains" of inheritance and development of folk culture. In short, folk culture products are developed from various folk culture resources. Folk products have broad development space. Once new products are established, we must achieve distinction in responsibility, rights and benefits, actively raise capitals, develop and produce. In this process, it is necessary to look from the long run, adhere to the combination of protection and development, so that the products will have long vitality.

\section{CONCLUSION}

In conclusion, developing folk products is the ideal way to develop, spread and inherit folk culture. It is an inevitable requirement of market economy to take the road of industrialization of folk culture. It is a great event in the development history of folk culture and has practical significance. In the course of construction of folk culture in Central Plains, there must be many difficulties and challenges, we must explore unceasingly, work steadfastly, update our thinking and concepts, correctly choose products, explicit the purpose of development, and then we will benefit a lot and organically combine the research of folk custom and the development of folk products, gain social benefit. At the same time, we can gain social benefit, ideal economic benefit and rush out a new road in the development field of folk products.

The regional competitiveness refers to the ability of an area to continuously create wealth. Nowadays, various countries in the world actively rush registration of folk culture. Folk culture is the carrier of national identification and the bond of national unity. Contradictions and disputes caused by cultural conflicts have become important factors that influence the peace and development of the world. Exploring the inheritance and innovation of folk culture has 
profound value and significance. Its harmonious values have increasingly become the core value of human in the era of globalization. Henan has abundant folk culture resources and broad prospect and advantages for development. In the process of inheritance and innovative development, Henan folk culture needs the helps of new culture type to form developmental scale and industrial effects. It is necessary to take folk culture as resources to face the market, fully discover and use various folk culture resources as far as possible, realize the change from resources to products, make it become cultural products with higher value and create more economic value.

\section{REFERENCES}

[1] Zhong Jingwen. Introduction to Folklore [M], Shanghai: Shanghai Literature and Art Publishing House

[2] Zhang Bangshu. Research on Concept of Information Literacy [J], Scientific and Technological Information (Scientific Research), the 17 th edition in 2007 